\title{
Forecasting Pharmaceutical Prices for Economic Evaluations When There Is No Market: A Review
}

\author{
Ilke Akpinar ${ }^{1}$ Philip Jacobs ${ }^{2,3} \cdot$ Tien Dat Tran ${ }^{3,4}$
}

Published online: 8 November 2016

(c) The Author(s) 2016. This article is published with open access at Springerlink.com

\begin{abstract}
Background Economic evaluation helps policy makers and healthcare payers make decisions on drug listing, coverage, and reimbursement. When economic evaluations are conducted before a product launch, the prices of the pharmaceuticals have to be forecast.

Objective The aim of this study was to examine the methods of establishing proxy prices and their accuracies compared with actual market prices after the product launch.

Methods We searched the literature for evaluations for drugs that were licensed in the US between 2010 and 2015. We reviewed the studies for the forecasting strategies used, and then estimated the difference between actual 2016 post-launch prices and what the proxy prices would be if the forecast was carried out in the US in 2016.

Results We identified six such studies, with seven drugs. Four studies used substitute drugs as proxies for the study drug, and three used other methods. The range of the values of actual minus proxy price varied considerably, and no trend was observed.

Conclusion Forecasting drug prices is as precarious as forecasting in other areas of the economy. We urge caution
\end{abstract}

Philip Jacobs

pjacobs@ihe.ca

1 Department of Pediatric Surgery, Antalya Training and Research Hospital, Antalya, Turkey

2 Department of Medicine, University of Alberta, Edmonton, $\mathrm{AB}$, Canada

3 Institute of Health Economics, Edmonton, AB, Canada

4 School of Public Health, University of Alberta, Edmonton, AB, Canada in reviewing and accepting a cost-effectiveness ratio that is based on forecast prices.

\section{Key Points for Decision Makers}

When pre-launch prices are estimated, the price of a close substitute is the most common variable used to estimate the prices of study drugs, followed by the price in a country where the drug is licensed.

Although sensitivity analysis is not widely used, it is an important component of a forecasting study.

In general, forecasted prices, when used in economic evaluations, have varied considerably from actual prices, especially when there is no close substitute on which to base the forecasted price.

\section{Introduction}

Economic evaluation helps policy makers and healthcare payers make informed decisions on drug listing, coverage and reimbursement [1]. Value consideration has also been proposed to be included in clinical guidelines [2]. In many countries, there is a wealth of information on pharmaceutical price data for use in economic evaluations, for drugs that have been licensed. Prices are important variables in their roles as budgeting variables, as well as components of economic evaluations. However, in some situations, product launch is delayed and, prior to a product launch, there is no publicly available pricing information for the study 
drug. This topic is of particular importance when the policy maker or manufacturer wants an advance study. In the absence of market prices, investigators have conducted economic evaluations, using proxies for the drug prices. Currently, little is known as to the accuracy of using proxy drug prices in economic evaluations. Accordingly, we reviewed the literature on those economic evaluations for pharmaceuticals that were published prior to product launch. In our review, we address two questions: (i) what methods have been used to establish proxy prices for the yet-to-be-launched pharmaceuticals; and (ii) how do the prices that result from these proxy pricing strategies compare with actual market prices, after the product launch.

\section{Methods}

We based our analysis on the US FDA list of newly licensed drugs from 2010 through 2015 [3]. For each newly licensed drug, we searched PubMed for any study published prior to the licensed year and that had the name of that drug (trade name or generic name) in the title. We then limited our sample to those articles that also included the words 'cost' or 'economic' in the title. All retained articles were examined and those that were economic evaluations were kept for further analysis.

We examined the retained economic evaluations for the strategies that the authors used to establish price proxies for the not-yet-licensed drugs, and used the proxy pricing strategy to estimate US 2016 proxy prices, which were then compared with the actual US prices.

We used the 2016 Federal Supply Schedule (FSS) pharmaceutical price list from the US Department of Veterans Affairs [4] as the primary source of actual and proxy prices, and obtained both prices for three drugs $\left(\right.$ Prolia $^{\circledR}$, Brilinta ${ }^{\circledR}$, and Xarelto ${ }^{\circledR}$ ) from this list. We used Canadian prices for the post-launch price of Grazax [5] as no US prices were available. Similarly, we obtained a postlaunch price of Surfaxin on a drug website as this drug is not listed in the US product list [6].

\section{Results}

We identified 17 potential studies in our initial literature scan and, after examining the abstracts, we eliminated nine of these studies for the following reasons: a foreign language (one study); the study was not an economic evaluation (one study); and the drug was previously licensed, possibly in a different country where the study was conducted (seven studies). Of the remaining eight studies, we further excluded two studies: one was a duplicate and one did not explicitly address non-licensed drug pricing, e.g. costs for all services, including drugs, were lumped together with no explanations. Six studies remained for analysis, with seven non-licensed drugs.

For the seven drugs, the following methods were used to determine proxy prices: the drug Grazax was licensed in another country (UK) and there was a listed UK price [7]; and the drug generic clopidogrel was given an assumed price [8] based on another study [9]. In one case of Ruconest ${ }^{\circledR}$ [10], the authors stated that they obtained the proxy price in consultation with the manufacturer, but no more details were provided. In four cases, the proxy price was determined using the listed price of a substitute drug $[8,11-13]$.

A comparison of drug and proxy prices is shown in Fig. 1. A substantial difference between actual and proxy price was noted in five of the seven drugs, but there was no uniformity in the results. In two of the three cases (Prolia ${ }^{\circledR}$ and Brilinta $^{\circledR}$ ), where FSS prices were available for the post-launch study drug and the proxy, the results were close, but in the third case $\left(\right.$ Xarelto $^{\circledR}$ ) the difference was $104.8 \%$. In one extreme case, the standard price could not be verified.

\section{Discussion}

Economic evaluations usually appear in print after a drug is licensed and thus a price is available. However, there have been instances where analysts have published economic studies before product launch, and thus drug prices that were used in the economic evaluation had to be forecast. We conducted a search of those instances where economic studies have appeared in print prior to US licensing, and identified seven cases where drug prices had to be forecast. We compared the actual 2016 US price (post-launch) with the 2016 US proxy price using the forecasting technique. Our results showed a considerable difference between prices using the forecasting technique and actual prices; however, no trend was observed.

This is the first study that compared forecast price with actual (post-launch) price. Information about the reliability of forecast prices is important if the prospective studies are to be used in listing decisions. In general, we would recommend caution in accepting a cost-effectiveness ratio that is based on forecast prices. If economic evaluations using forecasted prices are used, then evaluations in which the study drugs have close substitutes may have better reliability. In addition, sensitivity analyses should always be used.

There are several limitations to consider. First, our analysis was based on a small sample. We did not find many studies using forecasted prices, therefore, generalizability is limited. Second, we compared 2016 actual prices with prices using forecasted methods and 2016 US price. 
Fig. 1 Ratio of actual minus proxy price, in relation to proxy price, 2016 values. Asterisk the proxy price was based on a substitute drug

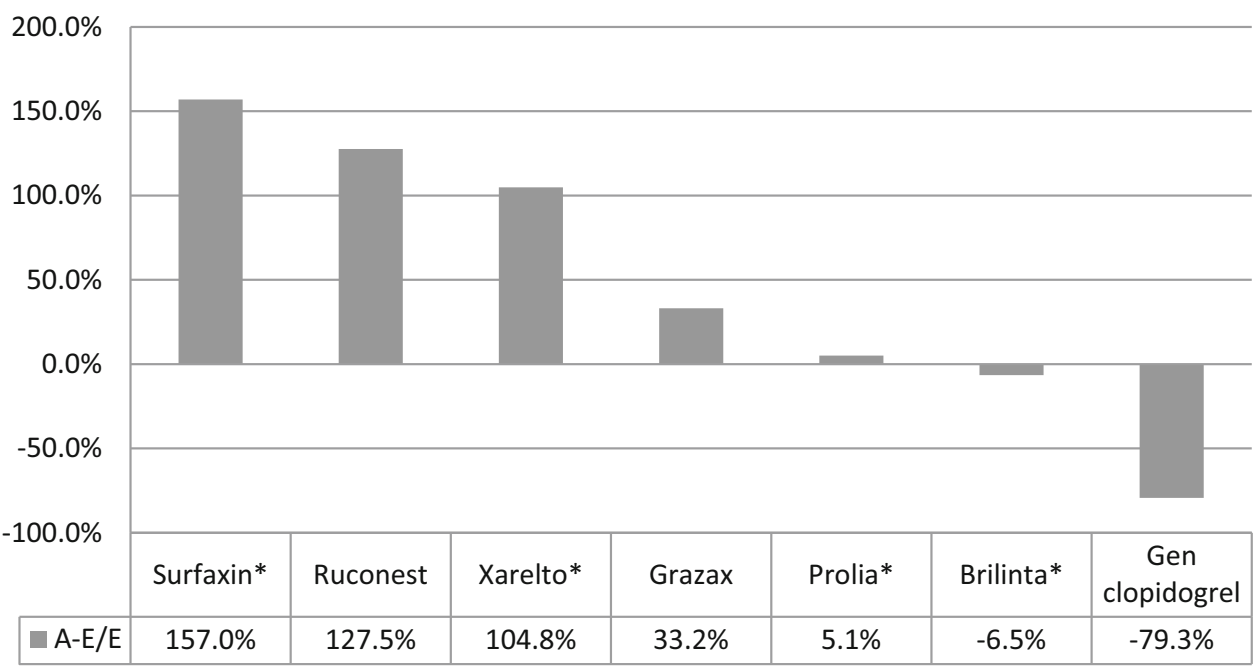

There were instances where foreign drug prices entered into the analysis, and these forecasts might not be as reliable. Third, when there are no close substitutes for the study drug, the forecast may be less reliable. In addition, cost effectiveness has both costs and effectiveness components, and for a complete forecast both must be present. We have focused on price forecasting only.

\section{Conclusions}

Forecasting is itself a risky business, and not just in the case of drug prices, where variances between forecasted and actual prices can lead to significant errors. It is important to be aware that these errors may be enhanced, especially when there are no close substitutes in the market. We urge caution in reviewing and accepting a costeffectiveness ratio that is based on forecast prices.

\section{Compliance with Ethical Standards}

Ilke Akpinar, Philip Jacobs, and Tran Tien Dat declare that they have no conflicts of interest and they received no financial support for this manuscript.

Author contributions Philip Jacobs conceptualized the study and drafted the manuscript; Ilke Akpinar conducted the literature search; and Tran Tien Dat carried out the drug pricing. All authors contributed to the writing of the manuscript and critically reviewed the manuscript for intellectual content.

Open Access This article is distributed under the terms of the Creative Commons Attribution-NonCommercial 4.0 International License (http://creativecommons.org/licenses/by-nc/4.0/), which permits any noncommercial use, distribution, and reproduction in any medium, provided you give appropriate credit to the original author(s) and the source, provide a link to the Creative Commons license, and indicate if changes were made.

\section{References}

1. Chambers JD, et al. The lag from FDA approval to published cost-utility evidence. Expert Rev Pharmacoecon Outcomes Res. 2015;15(3):399-402.

2. Anderson JL, et al. ACC/AHA statement on cost/value methodology in clinical practice guidelines and performance measures: a report of the American College of Cardiology/American Heart Association Task Force on Performance Measures and Task Force on Practice Guidelines. J Am Coll Cardiol. 2014;63(21):2304-22.

3. US FDA. US FDA list of newly licensed drugs (2010-2016). 2016. http://www.centerwatch.com/drug-information/fda-approvals/. Accessed 6 Jun 2016.

4. Office of Acquisition and Logistics, US Department of Veterans Affairs. Pharmaceutical prices. 2016. http://www.va.gov/oal/ business/fss/pharmPrices.asp. Accessed 6 Jun 2016.

5. Pharmacy Checker. Grazax 75000 unit prices-brand version. 2016. http://www.pharmacychecker.com/brand/price-comparison/ grazax/75000+unit/. Accessed 8 Jun 2016.

6. Blink Health. Surfaxin. 2016. https://www.blinkhealth.com/ surfaxin. Accessed 8 Jun 2016.

7. Dranitsaris G, Ellis AK. Sublingual or subcutaneous immunotherapy for seasonal allergic rhinitis: an indirect analysis of efficacy, safety and cost. J Eval Clin Pract. 2014;20(3):225-38.

8. Crespin DJ, et al. Ticagrelor versus genotype-driven antiplatelet therapy for secondary prevention after acute coronary syndrome: a cost-effectiveness analysis. Value Health. 2011;14(4):483-91.

9. Mahoney EM, et al. Cost-effectiveness of prasugrel versus clopidogrel in patients with acute coronary syndromes and planned percutaneous coronary intervention: results from the trial to assess improvement in therapeutic outcomes by optimizing platelet inhibition with prasugrel-thrombolysis in myocardial infarction TRITON-TIMI 38. Circulation. 2010;121(1):71-9.

10. Kawalec P, Holko P, Paszulewicz A. Cost-utility analysis of Ruconest $^{\circledR}$ (conestat alfa) compared to Berinert ${ }^{\circledR} \mathrm{P}$ (human $\mathrm{C} 1$ esterase inhibitor) in the treatment of acute, life-threatening angioedema attacks in patients with hereditary angioedema. Postepy Dermatol Alergol. 2013;30(3):152-8.

11. Kwong LM. Cost-effectiveness of rivaroxaban after total hip or total knee arthroplasty. Am J Manag Care. 2011;17(1 Suppl):S22-6. 
12. Hiligsmann M, Reginster JY. Potential cost-effectiveness of denosumab for the treatment of postmenopausal osteoporotic women. Bone. 2010;47(1):34-40.
13. Gdovin JM, et al. A comparative pharmacoeconomic assessment of two surfactants for the prevention of respiratory distress syndrome. J Pediatr Pharmacol Ther. 2006;11(1):43-54. 